\title{
POTENTIAL OF IMAGE OPTIMIZATION ON WEBSITES OF RURAL TOURISM FACILITIES IN POLAND
}

\author{
Karol Król ${ }^{1 凶}$, Dariusz Zdonek² \\ ${ }^{1}$ University of Agriculture in Krakow, Poland \\ ${ }^{2}$ Silesian University of Technology in Gliwice, Poland
}

\begin{abstract}
The success of a rural tourism business largely depends on promotional activities. Having developed a tourist product, owners of rural tourism facilities should therefore inform the buyers about it. Usually, they rely on websites and social media for this purpose. However, for a website to fulfill its function, it should be of high quality. The improvement of website quality can be achieved through measures which include search engine optimization (SEO) and content and graphics optimization. The purpose of this paper is to assess the potential of image optimization on websites of Polish rural tourism facilities. The research covered 1000 paid domain websites. The largest part of the sites surveyed were rated good in terms of graphic file optimization. In spite of this, it was possible to reduce the size of graphic files covered by this study and used in the research model by as much as $67 \%$ without significantly deteriorating their quality. This research showed that image optimization has no direct impact on the outcome of an SEO audit, and that images can be optimized even for websites with high final scores.
\end{abstract}

Keywords: rural tourism, optimization, quality, digital marketing, promotion

\section{INTRODUCTION}

Rural tourism, an umbrella term for all kinds of tourism economy in rural areas, is perceived as an important development path for these areas (Das and Rainey, 2010). Notably, it is a method of economic and social activation for rural inhabitants that supports the sales of agricultural products while simultaneously affecting public perception of the countryside and agriculture (Tew and Barbieri, 2012; Barbieri, 2013). Tourism is sometimes seen as a panacea for the problem of Polish rural areas. It is intended to provide additional income streams, be an alternative to agricultural activity, and enable a more efficient use of agricultural resources. In practice, rural tourism activities are conducted in various ways and take various forms, from non-working farm indirect interaction (which does not involve agricultural activities) to working farm direct authentic interaction (Flanigan et al., 2014). Whatever the case may be, the success of rural tourism business largely depends on promotional activities (Santeramo, 2015). Having developed a tourist product, owners of rural tourism facilities (including agritourism farms) should therefore inform the potential buyers about it. Research has shown that owners of rural tourism facilities most often use the potential of websites and social media for this purpose (Ammirato, 2010; Jones et al., 2015). However, for a website to fulfill its function, it should be of high quality (Król, 2019), especially when it comes to the development technology, usability and content (Leite et al., 2014).

\section{PURPOSE AND GOALS OF THE STUDY}

The term "quality" is derived from ancient times, from the Greek "poiotes" (Latin "qualitas"), and is an extremely wide and ambiguous concept. The many factors

$\bowtie$ Karol Król, Faculty of Environmental Engineering and Land Surveying, University of Agriculture in Krakow, al. Mickiewicza 24/28, 30-059 Kraków, Poland, e-mail: k.krol@onet.com.pl; https://orcid.org/0000-0003-0534-847 I 
which influence the quality of a website can be grouped as follows: internal (on-site) factors, relating to the usable quality of the site; and external (off-site) factors, relating to the site's environment, e.g. the number of inbound links. The minimum quality standards can be met by complying with technical requirements (e.g. W3C standards), requirements for quality assurance processes, quality standards for interactive services and systems (e.g. WCAG standards), and legal regulations for the provision of specific service types.

The quality of a website can be assessed through what is referred to as a site audit. In general terms, an audit means an evaluation of an organization, system, process, project or product by independent experts. The subject of the audit is examined for compliance with certain standards, reference models, checklists, legal provisions or benchmarks. Auditing is a recognized management technique providing managers with an overview of the present situation of specific resources and services within an organization. Auditing the website allows to assess whether it meets project standards and user expectations. It is usually performed to detect critical points which, if optimized, may contribute to an increase in goal conversion rates (Król, 2018).

There is no one commonly accepted website auditing routine. Usually, it is an expert service which differs in nature depending on the auditor's skills. Many designers and testers of website effectiveness develop their own assessment criteria based on their experience and professional practice. The audit is based on tools and methods, including various test automation applications. The results of individual tests are presented using point notes, letters or graphics. Audit details are included in the final report which may also contain a list of post-audit recommendations.

In principle, website audits can be divided into: (1) search engine optimization (SEO) audits; (2) content audits and (3) usability audits. Site engineering audits ("technical audits") and audits of graphic elements are also a frequent practice although they can be part of the development technology audit. SEO, content and usability audits are increasingly frequent. Graphical audits are less common, even though image optimization may translate into improved site performance. The purpose of this paper is to assess the potential of image optimization on websites of Polish rural tourism facilities.

\section{THEORETICAL BACKGROUND}

In mid-1990s, the world of the Internet was transformed with the development of search engines which made the overwhelming Web resources accessible not only to academic users but increasingly to the general public and commercial enterprises (Zhang and Dimitroff, 2005a). Over the last few years, searching for online information has become a ubiquitous and a critically important activity for many products and services. Many Internet visitors now access websites from a search engine instead of through a direct link from another web page (Shih et al., 2013).

Website quality is reflected by a good indexing and positioning in search engines. There are various factors which can contribute to visibility of a webpage in a search engine results list, for example: webpage metadata structure (Zhang and Dimitroff, 2005b) or webpage content; webpage visibility can be improved by increasing the frequency of keywords in the title, in the full-text and in both the title and full-text (Zhang and Dimitroff, 2005a). The website's quality has a direct and positive impact on customer satisfaction which, in turn, has a direct and positive impact on the intention to purchase goods or services (Ali, 2016). The improvement of website quality and visibility in the search results can be achieved through measures which include optimization (in broad terms), with particular focus on search engine optimization and content and graphic files optimization.

\section{Website optimization for search engines}

SEO can be clearly noticed to grow in popularity (Berman and Katona, 2013), and is a booming field for entrepreneurs. Hundreds of companies offer search engine optimization services to help enhance customers' online experiences by pushing relevant websites to the fore. At the same time, an increasing number of websites are turning to search engines as their primary marketing route. Search engine optimization (SEO), or search engine positioning, is the process of identifying factors in a webpage which would impact search engine accessibility to it and fine-tuning the many elements of a website so it can achieve the highest possible visibility when a search engine responds to a relevant query (Zhang and Dimitroff, 2005a). SEO is a method for creating or altering a web page in an optimized fashion so that it will appear more relevant than other pages to the search engine (Shih et al., 2013). Search engine optimization aims at 
achieving good search engine accessibility for web pages, high visibility in a search engine result, and improvement of the chances the web pages are retrieved (Zhang and Dimitroff, 2005a). SEO can be broken down into five major categories: keyword, research and selection, getting the search engine to index the site, on-page optimization, and off-page optimization (Malaga, 2008).

SEO audit represents an analysis to the problems faced by a web page about to be optimized and the solutions to them. It represents the procedure of analysis of the characteristics of a website that are important for obtaining a better positioning in the search engines and is the first procedure in the list of activities specific to the process of optimization. A SEO audit should contain information primarily related to the recommendations for solving the problems identified (Nen et al., 2017).

\section{Website usability audit}

The quality of the site, effectiveness, efficiency, and browsing experience are determined by the development technology, the uniqueness and topicality of the content it presents, and the form of its presentation, often referred to as the usable quality of a website. The content should be diverse and complete, natural, unique, and complemented by graphic and video materials. Moreover, the content should be useful because only useful content is able to attract users to the site and make them stay there (Oliveira and Casais, 2019). The usefulness of the website is related to the concept of "user experience" (UX), which describes the user's feelings that appear in contact with a given product, system (computer) or service. User experience can be a distinguishing feature of a product or service against the background of competitive solutions and an announcement of their high quality. UX combines designing visual components ("UI design," user interface design) with designing and testing communication processes. It is a broader concept than usefulness because it also includes aspects of user interaction with the organization, its services and products, as well as thoughts, observations and emotions connected with it (user experience assessment, UXA). In turn, user-oriented design focuses on positive experiences resulting from the comfort of using the website, which should also be visually appealing.

There are many factors that affect website user experience, including: (1) navigability, (2) website functionality, (3) website consistency, (4) simplicity, (5) readability and (6) supportability (Garrett, 2011). Website usability can be examined using usability evaluation and expert evaluation. A heuristic evaluation (Masip et al., 2011) and what is referred to as the usability checklist (with design guidelines), i.e. a list of good practices called "heuristics," may be helpful in the latter routine (Nielsen and Mack, 1994). A heuristic analysis facilitates the "cognitive walkthrough" which tests the website by performing actions according to a test scenario.

\section{Graphic file audit and optimization}

Graphic file optimization has a large potential which, if leveraged, can contribute to the growth of organic traffic. Graphic optimization can be considered in terms of search engines or as a reduction of the size of files (compensation approach) which can have a bearing on the usability of the site. Graphic file optimization primarily means reducing their size expressed in kilobytes (file compression). Image compression research aims at reducing the number of bits needed to represent an image (Durai and Saro, 2006). Image processing algorithms are getting better, and lossless compression significantly reduces the weight of the file with little or no loss of quality. The compression of graphic files affects the speed of loading the site in the browser window.

Optimizing graphic files means more than just reducing their size; it also includes supplementing the alternative description (alt = "Agritourism Ostoja") and title of the graphic file (title = "family apartment") which should refer to its content or role. This may have an important impact on how the site is ranked in search results. Also, it is advisable that the graphic elements appear in their original size (in pixels) in the site. Reducing the graphic file on the fly, i.e. letting the browser handle it by interpreting file attributes, has an adverse effect.

The 'alt' (alternative text) attribute is a basic attribute of an image file that is part of a hypertext document. It has three main functions: (1) adding alternative text to photos (a fundamental principle of web accessibility); visually impaired users using screen readers will be read an alt attribute to better understand an on-page image; (2) alt tags will be displayed in place of an image if an image file cannot be loaded; (3) alt tags provide better image context/descriptions to search engine crawlers, helping them to index an image properly. In addition, the file name, which should refer to the content presented by the image, is of great importance. A file name such as "DSC_5660.jpg" does not say much about it neither 
to the user nor to search engine robots. Instead, a name referring to the graphic content, e.g. "apartment.jpg," clearly indicates what it presents.

\section{MATERIAL AND METHODS}

This research focused on individual sites of Polish rural tourism facilities. Rural tourism facilities include agritourism farms that run a service activity consisting in renting rooms, houses and holiday homes, selling meals and various products, and providing other services related to the stay of tourists. At the same time, they run agricultural activities differing in type and extent.

The research covered 1000 (one thousand) paid domain websites, including national domain (.pl), European, commercial, regional and other websites hosted at subscription domains (Król, 2017). Website addresses were retrieved from the Google search engine (based on what is referred to as organic search) and from the rural tourism directory available at agroturystyka.pl, the website of the Polish Federation of Rural Tourism "Hospitable Farms." The Google search engine was selected because of its great popularity worldwide (Dergiades et al., 2018).

Although web developers spend their time writing hypertext byte by byte, the Internet is mostly composed of images. It is hard to overstate the effect that images have on the average web page's performance; faster websites have broader reach and a higher impact. The first and most important thing that can be done to improve the performance of the website's images is to figure out how to measure them (Portis, 2017).

The tests used the Cloudinary Website Speed Test Image Analysis Tool (IAT) (webspeedtest.cloudinary. com). The Website Speed Test application analyzes website images and provides a ranking for a variety of image aspects and categories. It uses a letter grade scale of A to F (Page Image Score, PIS) which attempts to capture all of the page's good and bad decisions and reduce them down to a single simple metric (Table 1). The average image score is calculated based on the average values of the format, fit and compression scores. While the letter grade reflects the number of mistakes (opportunities for improvement) made in the page, it does not so much care about their magnitude. Along with the ranking, the Website Speed Test tool provides measurable information about how to go beyond simple compression to optimize web performance. The application helps discover how changing the image size, format selection, quality and encoding parameters can improve the web page's loading speed. It analyzes images that are defined in the web page as $<$ img $>$ elements and all background images except for those tagged as "background-repeat: round." The analysis is limited to 50 highest-resolution images found in the web page.

Rural tourism websites were also assessed for search engine optimization. The assessment procedure was an SEO audit carried out with selected test automation applications: (1) pozycjonowanie.pl (grade scale of 1 to 5), (2) ZadroWeb SEO Auditor (grade scale of 0 to 100) and (3) Sunspot SEO Audit (grade scale of 0 to 170). This allowed to describe each of the websites with three independent indicators of search engine optimization. The results were reduced to one F-Score coefficient using the zero unitarization method, as per formula (1):

$$
x_{i j}^{\prime}=\frac{x_{i j}-\min _{i}\left\{x_{i j}\right\}}{\max _{i}\left\{x_{i j}\right\}-\min _{i}\left\{x_{i j}\right\}}
$$

$$
\begin{aligned}
& i=1,2, \ldots, n ; j=1,2, \ldots, m \\
& x_{i j}^{\prime}: \text { standardized diagnostic variable } \\
& x_{i j}: \text { non-standardized diagnostic variable } \\
& \min _{i}\left\{x_{i j}\right\}: \text { minimum value of the non-standardized diag- } \\
& \quad \text { nostic variable } \\
& \max _{i}\left\{x_{i j}\right\}: \text { maximum value of the non-standardized di- } \\
& \quad \text { agnostic variable. }
\end{aligned}
$$

Table 1. Grade scale used in the audit of graphic files

\begin{tabular}{lccccc}
\hline \multicolumn{1}{c}{ Verbal evaluation } & Excellent & Good & Mediocre & Poor & Very poor \\
\hline Score & 6 & 5 & 4 & 3 & 2 \\
Letter-grade rating (page image score) & A & B & C & D & E \\
\hline
\end{tabular}

Source: own elaboration based on the Cloudinary Website Speed Test point scale. 
Król, K., Zdonek, D. (2020). Potential of image optimization on websites of rural tourism facilities in Poland. J. Agribus. Rural Dev., 1(55), 29-36. http://dx.doi.org/10.17306/J.JARD.2020.01195

Table 2. Descriptive statistics

\begin{tabular}{ccccc}
\hline $\begin{array}{c}\text { Statistical metric or indicator } \\
(n=1000)\end{array}$ & Page image score & $\begin{array}{c}\text { Total images } \\
\text { analyzed }\end{array}$ & $\begin{array}{c}\text { Total image size } \\
(\text { MB })\end{array}$ & $\begin{array}{c}\text { Potential compressed size } \\
(\%)\end{array}$ \\
\hline Average & 4.691 & 19.987 & 1.788266 & 33.3624 \\
Median & 5 & 15 & 0.886 & 30.95 \\
Min & 2 & 1 & 0.002 & 0.5 \\
Max & 6 & 163 & 48 & 97.7 \\
Total & 4691 & 19987 & 1788.266 & 33362.4 \\
\hline
\end{tabular}

Source: own elaboration.

Zero unitarization allows to standardize different ranges of variables and bring them to a synthetic, unitless cumulative final score (Balcerzak, 2015). Next, the strength of dependencies between the degree of graphic file optimization and the degree search engine optimization was examined using the Pearson's linear correlation coefficient.

\section{RESULTS}

The sites covered by this research had 19,987 graphic files with a total size of $1788.3 \mathrm{MB}$. The average size of a graphic file was ca. $89 \mathrm{~KB}$. On average, there were $1.8 \mathrm{MB}$ of graphic files per site, with a median of $0.89 \mathrm{MB}(\min =0.002 \mathrm{MB}, \max =48 \mathrm{MB})$. On average, there were 20 graphic files in the websites tested (with a median of 15), with the highest number (163) found in one of the sites (Table 2).

Most of the sites covered by this research were rated good in terms of graphic file optimization (Page Image Score $=$ B, Good, 5). These sites accounted for $67 \%$ of the total sample (Fig. 1). The websites rated as mediocre were half of the collection. (Page Image Score $=\mathrm{C}$, Mediocre, 4). They constituted ca. $30 \%$ of the set. Extreme scores (the best Page Image Score = A, Excellent, 6; and the worst Page Image Score $=$ D or E, Poor, 3 or 2) were much less frequent in the audit. The median Page Image Score was 5, and the average value was 4.69 (the range was from 2 to 6 ).

Assuming that the initial (base, primary) size of graphic files in the group covered by this study is $100 \%$, this research shows that the optimization (compression) of graphic files would allow reducing their size by up to $67 \%$. Thus, in the group covered by this study and in this research model, it was possible to reduce the size of graphic files from 1788.3 MB to as low as $590 \mathrm{MB}$ without significantly deteriorating their quality. On average, the size of graphic files in each site could be reduced by $66.6 \%$.

The large sample size allows to reveal relationships with a small correlation coefficient $(0.22-0.17$, Combs, 2010; or even 0.09, Starbuck, 2016). The values of the Pearson's linear correlation coefficient $(r)$ observed in

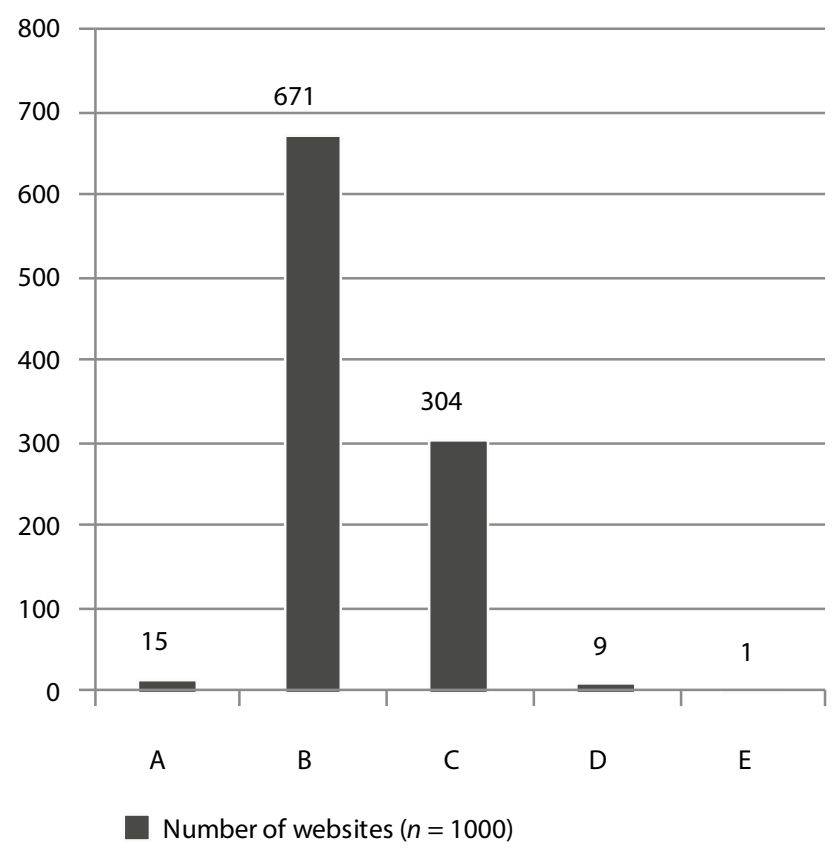

Fig. 1. Number of websites of rural tourism facilities grouped by score earned in the graphic file audit.

Source: own elaboration based on research. 
this research were very low. There was no linear relationship between Page Image Score and the F-Score indicator $\left(r=0.041, n=1000, \alpha=0.05, r^{2}=0.001, p>\alpha\right)$, i.e. between the degree of graphic file optimization and the degree of general site optimization. There was also no linear relationship between the size of graphic files (expressed in MB) and the F-Score indicator. The lack of linear dependence may suggest that the size of graphic files did not significantly affect the final SEO score.

None of the testing tools used did audit the degree of image optimization as part of the SEO audit. Images were audited to a certain extent as part of the site performance audit which is often equated with the loading speed of the site in the browser window. Finally, it can be concluded that websites achieve a different degree of search engine optimization while also differing in the degree of image optimization, and there is no linear relationship between these attributes.

\section{DISCUSSION}

Image Analysis Tool (IAT) is a tool that audits graphic files and indicates whether they may be compressed (which has the effect of improving the efficiency of the site). However, it does more than just that. Note that the main functionality of an application can be only a means to achieve the goal which, in turn, may be the acquisition of the user/client and, ultimately, the conversion of a user into a client (target conversion) (Schlosser et al., 2006). IAT is a tool branded by Cloudinary (Image and Video Management Solutions), a media management platform intended for web and mobile app developers. Cloudinary provides a package of free services, but more options are offered in subscription packages. This makes the Image Analysis Tool a useful marketing tool which builds the image of the Cloudinary brand. Also, it acts as what is referred to as the so-called scraping infrastructure by acquiring traffic (users) from the Internet. They get the chance to use the tool, get to know the Cloudinary brand, and maybe some of them will opt for the paid solutions. At this point, one may ask about the reliability of the results of such an audit. Can the results be manipulated to emphasize the need for image compression and at the same time indicate a solution to the problem in the form of Cloudinary? This is unlikely and, above all, it would be unprofessional. The application is publicly available. Manipulations would be quickly detected by Internet users who do not forgive such behavior. In addition, the Image Analysis Tool is integrated with the WebPageTest application (webpagetest.org). Website Speed Test is a tool developed by AOL, made available in 2008 and still being developed. This application has a good international reputation in the SEO/SEM industry, and provides a link to the Image Analysis Tool on its website. It is therefore a kind of "vote of confidence" for IAT.

Even a few seconds delay is enough to induce a negative impression of the website users. During delays, the system operation is lost, users lose full control and are forced to wait for a computer (device). A website that loads in 5 seconds gets $35 \%$ fewer impressions and a $105 \%$ higher bounce rate. This delay reduces target conversion by up to $38 \%$. Research has shown that in 2006, an average Internet client expected that the site will be loaded in the browser window within 4 seconds. In 2010, the same client already expected that the page will be loaded within 2 seconds or faster (Bixby, 2010).

Research done in 1997 showed that large graphic files were the main cause of delays recorded on websites. However, currently, the slow loading of websites is usually caused by server delays, too many components used, or too many fancy widgets (Nielsen, 2010). The tests have confirmed this. Over $67 \%$ of tested sites have recorded satisfactory sized images. Therefore, the potential delays in loading websites in the browser window may have resulted from other factors, including server delays. This is a topic for future research that can be carried out in terms of measuring site performance and the relationship between performance and the degree of image optimization.

\section{PRACTICAL IMPLICATIONS}

The websites of rural tourism facilities included graphic files, the size of which could have been reduced in most cases. However, research has shown that in many cases this was not a necessity but could be done voluntarily. At this point, it is worth noting that while optimization is basically beneficial, there should actually be a rationale behind it. In this case, searching for every kilobyte of data which could slim down the site would be unjustified, primarily due to the function and the small number of visitors of the sites of rural tourism facilities (see Król and Halva, 2017). Significant effects of small data compression are usually achieved with large websites with numerous functionalities. Owners of rural tourism 
facilities should pay special attention to the size of graphic files when ordering (developing) a new site and when updating it. These are sensitive moments when excessively large images are likely to be published in the structure of the site, and may affect the performance of the entire website.

Graphic files should be audited regularly, especially if the site has many visitors and is updated frequently. It may turn out that the new content includes a large graphic file which will have a negative impact on website performance. However, this may be troublesome for owners of rural tourism facilities who usually do not have the knowledge and skills necessary to audit and optimize websites. A proactive approach is therefore recommended which means avoiding posting large graphic files. Preventive actions should be preceded by an evaluation of the current condition. One of the supporting applications of the site performance audit can be used for this purpose.

The lack of image optimization may have particularly negative consequences for users who look for rural tourism offerings on the Internet using their mobile devices. In their case, the amount of data sent over the network and the associated data compression are of critical importance (see Oh and Fox, 2007). Mobile devices are particularly sensitive to large graphic files that can significantly impede or even prevent browsing the site.

\section{SUMMARY}

In the group of websites covered by this study, an excessive size of graphic files was not a pressing problem. However, this probably was not the result of informed decisions made by the owners of rural tourism sites. Usually, these websites are online business cards which by nature are rarely updated and do not present news. Various reports from events organized in the facility etc. are usually posted in social media whereas the website only presents the offering. If no content is posted, there are no opportunities for publishing large-sized graphics. Therefore, the relatively satisfactory status of image compression may result from the main functions that are usually delivered by the sites of rural tourism facilities, i.e. marketing, information and contact.

Optimization is a procedure that can always be carried out, even if a site has a satisfactory Page Image Score. However, this is a synthetic cumulative indicator which is the result of averaging the measurement of selected attributes of many graphic files. Thus, the size of the graphic file that will require optimization is likely to be included. However, at the same time, it will not significantly affect the value of the indicator. Note also that the calculation of the Page Image Score also relies on that principle. Therefore, despite the positive result of the audit, it should be remembered that it was performed in an algorithmic and automated manner and, as such, it needs to be analyzed and interpreted.

\section{REFERENCES}

Ali, F. (2016). Hotel website quality, perceived flow, customer satisfaction and purchase intention. J. Hospit. Tour. Techn., 7(2), 213-228. Retrieved from: https://doi.org/10.1108/ JHTT-02-2016-0010

Ammirato, S. (2010). An empirical study of agritourism evolution and e-commerce adoption challenges. Inf. Techn. Tour., 12(1), 89-104. Retrieved from: https://doi.org/10.3 727/109830510X12747489979664

Balcerzak, A. P. (2015). Europe 2020 strategy and structural diversity between old and new member states. Application of zero-unitarization method for dynamic analysis in the years 2004-2013. Econ. Soc., 8(2), 190-210. Retrieved from: https://doi.org/10.14254/2071-789X.2015/8-2/14

Barbieri, C. (2013). Assessing the sustainability of agritourism in the US: A comparison between agritourism and other farm entrepreneurial ventures. J. Sust. Tour., 21(2), 252-270. Retrieved from: https://doi.org/10.1080/096695 82.2012 .685174

Berman, R., Katona, Z. (2013). The role of search engine optimization in search marketing. Market. Sci., 32(4), 644-651. Retrieved from: https://doi.org/10.1287/ mksc. 2013.0783

Bixby, J. (2010). Cheat Sheet: Everything you wanted to know about web performance but were afraid to ask. Web Performance Today. Retrieved from: https://bit.ly/ per-formance

Combs, J. G. (2010). Big samples and small effects: let's not trade relevance and rigor for power. Acad. Manag. J., 53(1), 9-13. Retrieved from: https://doi.org/10.5465/ amj.2010.48036305

Das, B. R., Rainey, D. V. (2010). Agritourism in the Arkansas delta byways: assessing the economic impacts. Int. J. Tour. Res., 12(3), 265-280. Retrieved from: https://doi. org/10.1002/jtr.752

Dergiades, T., Mavragani, E., Pan, B. (2018). Google Trends and tourists' arrivals: Emerging biases and proposed corrections. Tour. Manag., 66, 108-120. Retrieved from: https:// doi.org/10.1016/j.tourman.2017.10.014 
Durai, S. A., Saro, E. A. (2006). Image compression with back-propagation neural network using cumulative distribution function. World Acad. Sci., Eng. Techn., 17, 60-64.

Flanigan, S., Blackstock, K., Hunter, C. (2014), Agritourism from the perspective of providers and visitors: A typologybased study. Tour. Manag., 40, 394-405. Retrieved from: https://doi.org/10.1016/j.tourman.2013.07.004

Garrett, J. J. (2011). The Elements of User Experience: UserCentered Design for the Web and Beyond. Second Edition. New Riders.

Jones, N., Borgman, R., Ulusoy, E. (2015). Impact of social media on small businesses. J. Small Bus. Ent. Dev., 22(4), 611-632. Retrieved from: https://doi.org/10.1108/ JSBED-09-2013-0133

Król, K. (2017). Internet domains promoting agrotourist farms. Tourism, 27(1), 23-29. Retrieved from: https://doi org/10.1515/tour-2017-0003

Król, K. (2018). Jakość witryn internetowych w zarządzaniu marketingowym na przykładzie obiektów turystyki wiejskiej w Polsce. Kraków: Stowarzyszenie Infrastruktura i Ekologia Terenów Wiejskich. Retrieved from: https:// doi.org/10.14597/INFRAECO.2018.3.2.057

Król, K. (2019). Forgotten agritourism: abandoned websites in the promotion of rural tourism in Poland. J. Hosp. Tour. Techn., 10(3), 461-472. Retrieved from: https://doi. org/10.1108/JHTT-09-2018-0092

Król, K., Halva, J. (2017). Measuring efficiency of websites of agrotouristic farms from Poland and Slovakia. Econ. Reg. Stud., 10(2), 50-59. Retrieved from: https://doi. org/10.2478/ers-2017-0015

Leite, P., Gonçalves, J., Teixeira, P., Rocha, Á. (2014). Towards a model for the measurement of data quality in websites. New Rev. Hyper. Mult., 20(4), 301-316. Retrieved from: https://doi.org/10.1080/13614568.2014.968638

Malaga, R. A. (2008). Worst practices in search engine optimization. Comm. ACM, 51(12), 147-150. Retrieved from: https://doi.org/10.1145/1409360.1409388

Masip, L., Granollers, T., Oliva, M. (2011). A heuristic evaluation experiment to validate the new set of usability heuristics. Inf. Techn.: New Gen. (ITNG). IEEE. Retrieved from: https://doi.org/10.1109/ITNG.2011.82

Nen, M., Popa, V., Scurtu, A., Unc, R. L. (2017). The Computer Management-SEO Audit. Rev. Int. Comp. Manag., 18(3), 297-307.
Nielsen, J. (2010). Website Response Times. Nielsen Norman Group. Retrieved from: https://goo.gl/MymMco

Nielsen, J., Mack, R. L. (1994). Usability Inspection Methods. New York: John Wiley \& Sons.

Oh, S., Fox, G. C. (2007). Optimizing Web Service messaging performance in mobile computing. Fut. Gen. Comp. Syst., 23(4), 623-632.

Oliveira, B., Casais, B. (2019). The importance of user-generated photos in restaurant selection. J. Hosp. Tour. Techn., 10(1), 2-14. Retrieved from: https://doi.org/10.1108/ JHTT-11-2017-0130

Portis, E. (2017). Introducing The Website Speed Test Image Analysis Tool. Smash. Mag., 7. Retrieved from: https:// goo.gl/9ssBrX

Santeramo, F. G. (2015). Research note: promoting the international demand for agritourism: empirical evidence from a dynamic panel data model. Tour. Econ., 21(4), 907-916.

Schlosser, A. E., White, T. B., Lloyd, S. M. (2006). Converting web site visitors into buyers: how web site investment increases consumer trusting beliefs and online purchase intentions. J.Mark., 70(2), 133-148. Retrieved from:https:// doi.org/10.1509/jmkg.70.2.133

Shih, B. Y., Chen, C. Y., Chen, Z. S. (2013). An empirical study of an internet marketing strategy for search engine optimization. Human Fact. Ergon. Manuf. Serv. Ind., 23(6), 528-540. Retrieved from: https://doi.org/10.1002/ hfm. 20348

Starbuck, W. H. (2016). 60th anniversary essay: How journals could improve research practices in social science. Admin. Sci. Quart., 61(2), 165-183.

Tew, C. H., Barbieri, C. (2012). The perceived benefits of agritourism: The provider's perspective. Tour. Manag., 33(1), 215-224.

Zhang, J., Dimitroff, A. (2005a). The impact of webpage content characteristics on webpage visibility in search engine results (Part I). Inf. Proc. Manag., 41(3), 665-690. Retrieved from: https://doi.org/10.1016/j.ipm.2003.12.001

Zhang, J., Dimitroff, A. (2005b). The impact of metadata implementation on webpage visibility in search engine results (Part II). Inf. Proc. Manag., 41(3), 691-715. Retrieved from: https://doi.org/10.1016/j.ipm.2003.12.002 